\title{
mGluR-dependent synaptic plasticity in drug-seeking
}

\author{
Camilla Bellone ${ }^{1}$ and Manuel Mameli ${ }^{2,3,4}$ * \\ 1 Department of Basic Neuroscience, University of Geneva, Geneva, Switzerland \\ 2 Institut du Fer à Moulin, Paris, France \\ 3 INSERM, UMR-S 839, Paris, France \\ ${ }^{4}$ Université Pierre et Marie Curie, Paris, France
}

\section{Edited by:}

Andrew Lawrence, Florey

Neuroscience Institutes, Australia

Reviewed by:

Kuei Y. Tseng, Rosalind Franklin

University of Medicine and Science,

USA

Christopher V. Dayas, University of

Newcastle, Australia

\section{${ }^{*}$ Correspondence}

Manuel Mameli, Institut du Fer à Moulin, UMRS-S 839 INSERM, 17 Rue du Fer à Moulin, Batiment Inserm, 75005 Paris, France.

e-mail:manuel.mameli@inserm.fr
A primary feature of drug addiction is the compulsive use despite negative consequences. A general consensus is emerging on the capacity of addictive substances to co-opt synaptic transmission and synaptic plasticity in brain circuits which are involved in reinforcement and reward processing. A current hypothesis is that drug-driven neuroadaptations during learning and memory processes divert the functions of these brain circuits, eventually leading to addictive behaviors. Metabotropic glutamate receptors (mGluRs) not only lead to long-term modulation of synaptic transmission but they have been implicated in drug-evoked synaptic plasticity and drug-seeking behaviors in two important ways. mGluR-dependent modulation of synaptic transmission is impaired by drug experience but interestingly their activation has been indicated as a strategy to restore baseline transmission after drug-evoked synaptic plasticity. Here we focus on the cellular mechanisms underlying mGluR-dependent longterm changes of excitatory synapses, and review results implicating these receptors in drug-evoked synaptic plasticity.

Keywords: mGluR, synaptic plasticity, addiction, long-term depression, AMPA receptors, NMDA receptor

\section{INTRODUCTION}

Significant evidence is converging to the idea that glutamatergic transmission plays a pivotal role in addictive-like behaviors (Kalivas, 2004; Gass and Olive, 2008). Studies employing rodent models suggest the use of metabotropic glutamate receptor (mGluR) modulators as a therapeutic strategy in treating drug addiction (Spooren et al., 2003). Importantly, the potential use of mGluR ligands lies in understanding the function of mGluRs at synapses in the central nervous system. These receptors are G-protein-coupled and classified in three groups according to their sequence homology (Pin and Duvoisin, 1995). However, drug development and fundamental research have focused their attention on Group I (mGluR-I) and Group II mGluRs (mGluR-II) as potential therapeutic targets. For this reason, in the present review we will focus on the properties of mGluRs and on the implication of mGluRI- and mGluR-II-dependent synaptic plasticity in the context of drug-seeking.

\section{GROUP I AND II mGLuRs}

mGluR-I are postsynaptically enriched at glutamatergic synapses. They couple to G-proteins of the $G_{\mathrm{q}} / \mathrm{G}_{11}$ family and activate phospholipase $C \beta$ leading to the hydrolysis of phosphotinositides followed by the generation of inositol 1,4,5trisphosphate and diacylglycerol. This canonical signaling cascade triggers calcium mobilization and activation of a broad range of downstream effectors, including protein kinase $\mathrm{C}(\mathrm{PKC})$ pathway, the mitogen-activated protein kinase/extracellular receptor kinase pathway, and the mammalian target of rapamycin/p70 S6 kinase pathway (Hou and Klann, 2004; Page et al., 2006). Activation of these secondary signaling cascades by mGluRI modulates both ion channel function and endocannabinoid
(eCB) synthesis (Kammermeier et al., 2000; Galante and Diana, 2004).

mGluRs-I comprises the mGluR1 and mGluR5 which are broadly expressed in the brain. Subcellular electron microscopy localized these receptors on the postsynaptic membrane in the perisynaptic zone (Lujan et al., 1997) where they regulate both inhibitory and excitatory synaptic transmission. Although both receptors are $\mathrm{G}_{\mathrm{q}}$-coupled, their signaling proprieties are different, suggesting distinct neuronal function (Choi et al., 2011).

mGluR-II (mGluR2 and mGluR3), are coupled to $\mathrm{G}_{\mathrm{i} / \mathrm{o}}$ proteins that inhibit adenylate cyclase and prevent the formation of cyclic adenosine $3^{\prime} 5^{\prime}$-monophosphate (cAMP). These receptors are predominantly expressed presynaptically (Niswender and Conn, 2010) and their activation can decrease neurotransmitter release via a cascade of events that engage voltage-gated calcium channels as well as SNAP-25-dependent mechanisms (Anwyl, 1999; Cartmell and Schoepp, 2000, Robbe et al., 2002a; Upreti et al., 2012).

The activation of these two subfamilies of mGluRs at excitatory synapses modulates the strength of synaptic transmission by inducing both long-term potentiation (LTP) and long-term depression (LTD) in various brain regions (Lüscher and Huber, 2010). In particular mGluR-dependent LTD has been extensively studied at various synapses and multiple induction mechanisms have been described to modulate the synaptic transmission in normal function as well as in diseases (Bellone et al., 2008).

\section{SYNAPTIC PLASTICITY AND DRUG-SEEKING}

Addictive drugs target the mesocorticolimbic dopamine (DA) circuit (Lüscher and Ungless, 2006) that originates in the ventral tegmental area (VTA), where DA neurons project mainly to the nucleus accumbens (NAc) and prefrontal cortex (PFC). A 
common feature of addictive drugs is their ability to trigger an increase in extracellular DA levels in VTA and projecting areas, and to cause adaptations both at glutamatergic and GABAergic synapses (Kauer and Malenka, 2007). These drug-evoked synaptic adaptations are, in the long run, able to reorganize the neural circuits, and may represent a fundamental cellular mechanism leading to addictive behavior (Lüscher and Malenka, 2011).

In the specific case of cocaine, it has been shown that acute and chronic drug exposure increases the ratio of AMPA and NMDA receptor mediated currents in different brain areas, suggesting an increase in synaptic efficacy at excitatory inputs (Thomas et al., 2001; Ungless et al., 2001, Dumont et al., 2005; Bellone and Lüscher, 2006).

Along with changes in AMPA and NMDA receptor mediated transmission, drug exposure alters mGluR-dependent synaptic plasticity. mGluRs-I and mGluRs-II have been implicated in these phenomena, as well as in drug-evoked behavioral adaptations (Olive, 2009) (Figure 1). However, a causal link between the synaptic and the behavioral observations remains elusive.

DRUG EXPOSURE IMPAIRS mGLUR-DEPENDENT PLASTICITY Addictive drugs alter mGluR-dependent synaptic plasticity in brain regions related to the mesolimbic system. In the NAc, the pharmacological activation of mGluRs-I by the agonist (S)-3,5dihydroxyphenylglycine (DHPG) promotes release of eCBs and reduces glutamate release via the activation of cannabinoid 1 (CB1) receptors, leading to a presynaptic form of LTD (Fourgeaud et al., 2004). A single in vivo exposure to cocaine or deltatetrahydrocannabinol transiently impairs this form of mGluRLTD (Fourgeaud et al., 2004; Mato et al., 2004) via the reduction of mGluR5 expression and the dysfunction of CB1Rs (Fourgeaud et al., 2004; Mato et al., 2004). The intermediate role of D1 receptor signaling seems to play a fundamental role in this cascade. The abolishment of this form of plasticity in the NAc may represent a mechanism to counteract the decrease in glutamatergic activity observed after cocaine exposure (Pierce et al., 1996). However, the overall cellular mechanism underlying cocaine-evoked reduction of mGluR5 protein and signaling remains unclear. Importantly, interplay between mGluRs and eCB may exist. As recently shown, a single cocaine injection impairs eCB-LTD in D2-containing MSNs in the NAc suggesting that cocaine may disrupt eCB-dependent synaptic plasticity via alterations in mGluR-signaling (Grueter et al., 2012).

An important role of mGluR5 has been as well established in the bed nucleus of stria terminalis (BNST), an integrative center implicated in stress and rewarding responses (Jalabert et al., 2009).

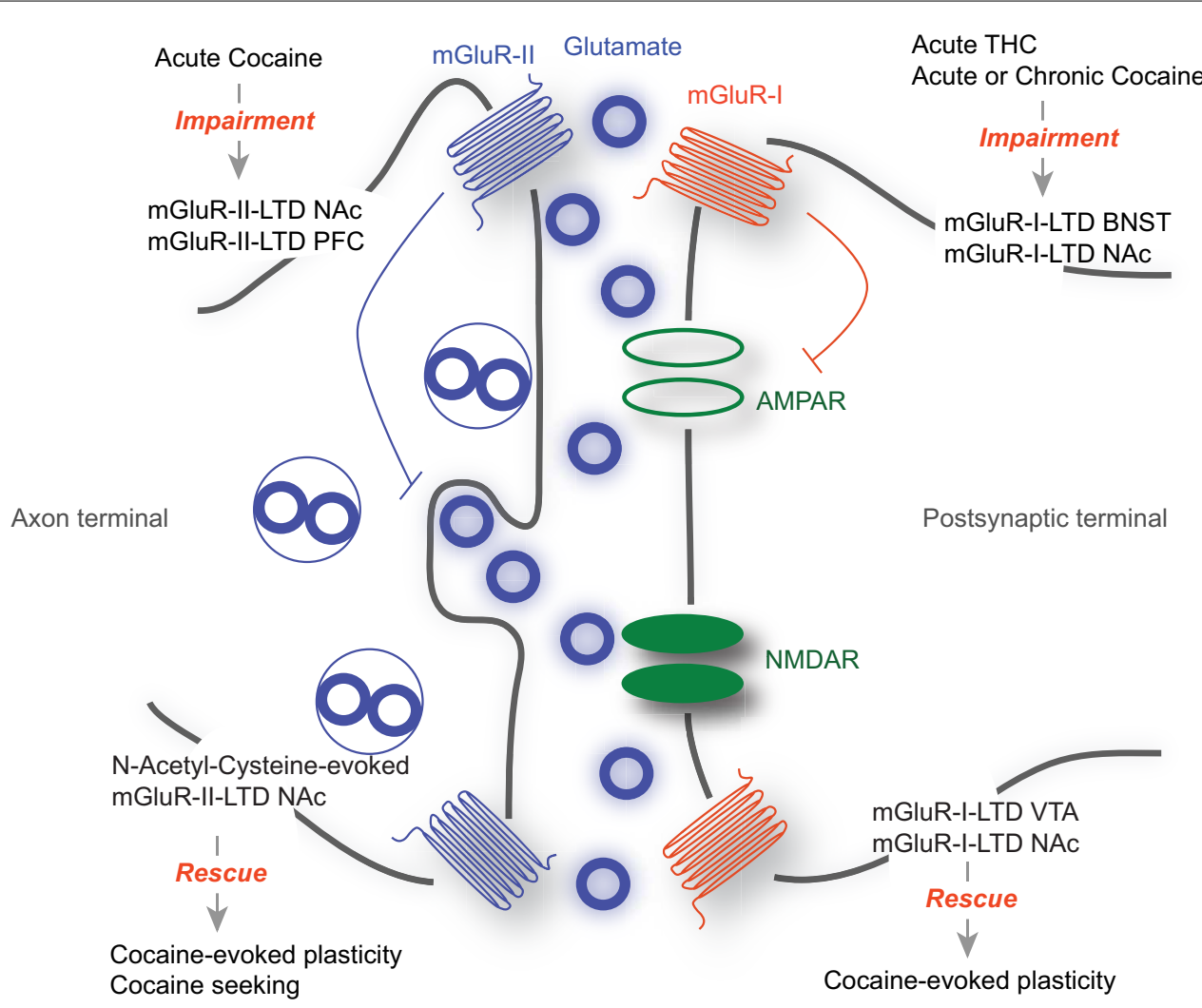

FIGURE 1 |The role of mGluR-LTD during drug-seeking. mGluR-I are mainly located at the postsynaptic membrane, while mGluR-II are mostly presynaptic. While mGluR-I-LTD has been extensively described as postsynaptic and occurring through the removal of AMPARs, mGluR-II LTD expression is presynaptic, involving a decrease in neurotransmitter release. Acute drug exposure or withdrawal abolishes mGluR-LTD in various structures including the BNST and the NAc (Top). On the other hand forms of mGluR-LTD are able to rescue drug-evoked synaptic plasticity and behavioral adaptations (Bottom). 
While a single cocaine injection does not alter mGluR-I-LTD in this region, chronic drug treatment impairs this form of plasticity $24 \mathrm{~h}$ after the last injection (Grueter et al., 2006). Indeed, decreasing the function in vivo of mGluR5 by using the specific antagonist MPEP, prevented cocaine-induced abolishment of the mGluR-ILTD (Grueter et al., 2008). Although the cascade of events has been partially characterized, it is so far unclear whether cocaine prevents the mGluR-I-LTD or whether it engages mGluR-dependent signaling occluding the synaptic plasticity. Therefore the mechanisms by which drug experience impairs mGluR-I-LTD in the BNST remain in part elusive.

The cellular adaptations described above occur days after drug exposure in virtually all treated animals and therefore they could represent an early mechanism for priming addictive behaviors. A critical step in the development of the disease is the shift from a recreational and controlled drug use to a compulsive drug taking despite negative consequences (American Psychiatric Association, 1994). Addiction can be modeled in animals, and rodent models have been established reflecting the human conditions. Indeed, only a restricted number of animals fulfill the hallmarks of drug addiction ("addict" vs. "non-addict") suggested by the Diagnostic and Statistical Manual of Mental Disorders (Deroche-Gamonet et al., 2004). This animal model has been recently employed to identify the biological traits of individual vulnerability to addiction.

Excitatory synapses onto MSN neurons of the NAc undergo two different forms of LTD: one is induced by mGluR-II activation and expressed presynaptically while the other is induced by NMDAR activation and expressed postsynaptically. While in "nonaddict" and "addict" animals the mGluR-II-LTD is unaffected, NMDAR-LTD is abolished in "addict" rats (Kasanetz et al., 2010). Interestingly, rats with a short history of cocaine seeking showed impaired NMDA-LTD, suggesting that while in "non-addict" rats synaptic function goes back to baseline, in "addict" rats the NMDALTD remains impaired. This suggests that this "anaplasticity," the inability to rescue normal baseline synaptic transmission, may represent a cellular locus for the shift to compulsive drug use (Kasanetz et al., 2010).

The glutamatergic afferents so far described remain elusive, however there are reasons to believe that they might be arising from cortical brain areas. Indeed, modulation of cortical inputs onto MSNs rescues cocaine-evoked synaptic and behavioral adaptations (Pascoli et al., 2012). Furthermore cortical brain areas are important in the control of drug intake (Kalivas et al., 2005). This evidence raises the hypothesis that alteration in mGluR-dependent synaptic plasticity can as well occur within the PFC. In a recent study, cocaine self-administration, in both "addict" and "nonaddict" rats abolished the eCB-LTD in the PFC (Lafourcade et al., 2007). On the other hand, a decrease in mGluR $2 / 3$ protein levels in "addict" animals impaired the induction of mGluR-II-LTD (Kasanetz et al., 2012). The specific impairment of mGluR-II-LTD in this animal model provides important insight for the role of mGluRs during the development of addiction. The observation in NAc and PFC supports a scenario in which the impairment of long-term synaptic plasticity in "addict" animals may represent a substrate for transition to addiction in interconnected structures of the mesocorticolimbic circuit.
As described above, many evidences described the impairment of mGluR-LTD in various regions of the mesocorticolimbic system at different time points of drug use. The interpretation of the data is however not trivial. How mGluR-LTD impairment may account for the development of complex behavior such as compulsive drug use? Linking "anaplasticity" with lack of flexibility in controlling drug use over time, while intriguing, may not represent the only explanation. Future studies would need to assess the cellular, molecular, genetic adaptations that occur in parallel with the impairment of mGluR-LTD during the development of drug addiction.

\section{RESCUE OF COCAINE-EVOKED PLASTICITY BY mGLuRs}

While many different forms of drug-evoked synaptic plasticity have been described in the mesolimbic system, several observations point to the capacity of mGluRs to reverse cocaine-evoked adaptations both in the VTA and in the NAc.

Drug-evoked synaptic plasticity occurs in the VTA within a few hours after drug exposure, it persists for about a week, and it is permissive for further adaptations in the NAc, suggesting a hierarchy in the drug-evoked synaptic plasticity (Argilli et al., 2008; Mameli et al., 2009). Three different parameters of synaptic transmission change early on after drug exposure. First, a single injection with cocaine, morphine, ethanol or nicotine increases the AMPA to NMDA ratio at excitatory synapses onto DA neurons (Ungless et al., 2001; Saal et al., 2003). This occurs concomitantly with a change in the subunit composition of AMPAR-mediated responses (Bellone and Lüscher, 2006). Indeed, the current-voltage relationship of AMPA receptor responses shows an inward rectification suggesting the insertion of GluA2-lacking calcium permeable AMPA receptors (CP-AMPARs) after drug exposure. The use of two-photon laser photolysis of caged glutamate further identified a decrease in function of NMDARs and altogether these synaptic changes contribute to invert learning rules (Mameli et al., 2011).

Interestingly the CP-AMPARs can be removed from the synapses both in vitro and in vivo. In slices from mice treated with a single cocaine injection, the agonist of mGluR-I, DHPG, induces a form of LTD that is expressed by the removal of CP-AMPARs and the insertion of calcium impermeable GluA2-containing (CI)AMPARs (Bellone and Lüscher, 2006). This suggests that drug exposure and in turn the presence of CP-AMPARs reveals a previously absent mGluR-LTD at these synapses. The mGluR-I-driven switch in AMPAR subunit composition restores baseline transmission and it relies on the de novo synthesis of GluA2 protein (Mameli et al., 2007). Since NMDAR function also changes after drug exposure, it will be important in the future to investigate whether the activation of mGluR-I also rescues transmission of NMDARs. Reversal of cocaine-induced synaptic plasticity occurs in vivo as well. Injection of a positive allosteric modulator of $\mathrm{mGluR} 1$ is able to remove CP-AMPARs, restoring basal transmission, and preventing more widespread changes downstream to the NAc (Bellone and Lüscher, 2006; Mameli et al., 2009). These observations led to the hypothesis that mGluR-I modulation represents a pharmacological tool to revert early drug-evoked plastic changes. Three major questions arise from these studies: (i) how does cocaine alter mGluR-signaling pathway? (ii) does the mGluR-I-LTD after 
insertion of CP-AMPARs occurs in other brain structures? and (iii) what is the behavioral implication of these early synaptic adaptations and its rescue by mGluR-I activation?

Susceptibility to relapse is a core component in the addiction process. Relapse can be modeled in rodents by exposing animals to drug-related cues after long withdrawal periods following self-administration, a paradigm termed incubation of craving (Lu et al., 2004). In acute slices containing NAc, synaptic GluA1 protein increases after 45 days of withdrawal following cocaine self-administration. These receptors were functional at synapses as indicated by the presence of inwardly rectifying AMPAmediated currents and by the sensitivity to specific CP-AMPARs open-channel blockers (Conrad et al., 2008; Mameli et al., 2009, McCutcheon et al., 2011b). In conclusion, the switch from CIAMPARs to CP-AMPARs at excitatory synapses onto MSN neurons of the NAc, may represent a cellular substrate for cocaine seeking. In addition to these observations, it has been recently shown that a new form of mGluR-I-LTD occurs after cue-induced cocaine craving in the NAc. While the activation of mGluR5 no longer induces the eCB-mediated LTD that is generally observed in drug naïve animals, mGluR1 activation induces a form of LTD that reverses the cocaine-induced accumulation of CP-AMPARs, restoring the initial AMPA-mediated transmission (McCutcheon et al., 2011a). This form of plasticity in the NAc depends on calcium/PKC signaling and therefore shows many common features with the mGluR-LTD described in the VTA (Bellone and Lüscher, 2005). Two important points remain still elusive: how does mGluR-signaling change upon cocaine experience? Is the mGluR-LTD a general feature of D1- and D2-expressing neurons in the NAc? These results together with future studies may provide insights to the appealing hypothesis that $\mathrm{mGluR} 1 \mathrm{~s}$ represent a gate controlling the levels of CP-AMPARs vs. CI-AMPARs. Indeed, a single drug exposure only transiently drives CP-AMPAR insertion in DA neurons of the VTA. In this case mGluR tone allows the system to recover baseline transmission in about a week. However, chronic cocaine treatment or self-administration overrides this key function such that endogenous activation of mGluR1 is not enough to restore basal transmission. This mediates more persistent changes in the VTA and the occurrence of synaptic adaptations in the NAc. Pharmacological boosting of mGluR1 function enables mGluR-I-LTD and in turns rescues baseline synaptic transmission in both VTA and NAc, suggesting a potential therapeutic impact at the behavioral level.

A further important role of mGluR-I-mediated plasticity has been recently shown at the developmental stage. The postnatal development of glutamatergic transmission requires $m$ GluR1 activation in the VTA switching CP-AMPARs to CI-AMPARs (Bellone et al., 2011). In utero cocaine exposure delays the synaptic maturation of both AMPAR- and NMDAR-mediated transmission in the offspring such that excitatory synapses onto DA neurons show CPAMPARs and GluN2B containing NMDARs beyond P14. Interestingly, the activation of mGluR1 in vivo by an allosteric modulator rescues the synaptic impairment induced by cocaine by inserting CI-AMPARs and GluN2A NMDARs. These observations led to the conclusion that in offspring from cocaine-exposed mothers, mGluR1 becomes inefficient to drive the postnatal maturation.

The role of rescuing drug-evoked synaptic abnormalities has also been proposed for mGluR-II. Repeated cocaine exposure alters the function of $\mathrm{mGlu} 2 / 3$ receptors and impairs the mGluR2/3-dependent plasticity both in the PFC and NAc (Xi et al., 2002; Huang et al., 2007, Xie and Steketee, 2008). As a consequence, both LTP and LTD are impaired in rats extinguished from cocaine self-administration for at least 3 weeks (Moussawi et al., 2009). Therefore, restoring the tone of mGluR2/3 would be able to rescue the ability of the excitatory synapses to induce LTP as well drug-seeking behaviors. For this purpose, $N$-acetylcysteine has been used as an indirect agonist of $\mathrm{mGluR} 2 / 3$ to restore glutamate homeostasis (Baker et al., 2003; Zhou and Kalivas, 2008). Acute administration of $\mathrm{N}$-acetylcysteine has been shown to prevent drug-seeking and to reverse synaptic transmission in NAc. Interestingly the activation of different mGluRs has opposite effects; while the direct pharmacological activation of mGluR2/3 prevents the relapse in the reinstatement model of cocaine, the activation of mGluR5 does not inhibit the cocaine seeking behaviors. On the contrary, block of mGluR5 prevents cocaine reinstatement for drug-seeking, suggesting dissociation between synaptic plasticity, and behavioral models. These somehow contrasting data require a further investment in the understanding of the roles of different mGluR subfamilies in modulating of drug-seeking behaviors.

\section{CONCLUDING REMARKS}

During the past decade our understanding of mGluR function has led to the development of a wide range of pharmacological and genetic tools that contributed to the discovery of the role of mGluRs in brain function. Many behavioral evidences suggested an important role of mGluR-signaling in cocaine reinforcement as well as cocaine extinction and reinstatement (Kumaresan et al., 2009; Wang et al., 2012). We focused here on mGluR-dependent plasticity, a key player in learning processes as well as in disorders of the nervous system. Much experimental evidence highlights the role of mGluR-LTD in mediating early (acute drug exposure) and late processes (chronic and self-administration paradigms), during the etiology of addictive behaviors. A big challenge in the field is to directly link specific synaptic modification to specific behaviors and, while a large effort has focused on the drug-evoked changes in mGluR-LTD after acute exposure to addictive substances, much work is still required to better probe the importance of mGluRLTD during the late phase of the disease. Future studies will need to investigate how changes in synaptic plasticity can lead to drug addiction. A feature in the etiology of addictive behaviors is the recruitment in a hierarchical fashion from ventral (VTA, substantia nigra, NAc) to dorsal (dorsal striatum) brain structures (Belin and Everitt, 2008; Mameli et al., 2009). mGluRs are largely expressed in the striatum, a region implicated in goal-directed behaviors, however the links between mGluR-dependent plasticity in this region and drug-seeking remain yet unknown.

Another important component of mGluR-I activation in the midbrain and in the striatum is the synthesis of $\mathrm{eCB}$, which mediate often short- as well as long-term presynaptic forms of plasticity. Drug exposure generally leads to an impairment eCB-LTD at both inhibitory and excitatory synapses, an effect that may contribute to drug-evoked behavioral adaptations. Further characterization of the interactions mGluRs, $\mathrm{eCB}$, and synaptic plasticity in the context of drug-seeking would be certainly important to probe the potential benefits of compounds targeting CBRs and eCB signaling. 
Finally determining the behavioral consequences of mGluRLTD-dependent rescue of plasticity and understanding whether inter-individual vulnerability to addiction lies in genetic, environmental-linked variation in mGluR function represents the major breakthroughs for the development of therapeutic strategies of addictive behaviors.

\section{REFERENCES}

American Psychiatric Association. (1994). Diagnostic Criteria from $D S M-I V$. Washington, DC: American Psychiatric Association.

Anwyl, R. (1999). Metabotropic glutamate receptors: electrophysiological properties and role in plasticity. Brain Res. Brain Res. Rev. 29, 83-120.

Argilli, E., Sibley, D. R., Malenka, R. C., England, P. M., and Bonci, A. (2008). Mechanism and time course of cocaine-induced long-term potentiation in the ventral tegmental area. J. Neurosci. 28, 9092-9100.

Baker, D. A., McFarland, K., Lake, R. W., Shen, H., Tang, X. C., Toda, S., and Kalivas, P. W. (2003). Neuroadaptations in cystine-glutamate exchange underlie cocaine relapse. Nat. Neurosci. 6, 743-749.

Belin, D., and Everitt B. J. (2008). Cocaine seeking habits depend upon dopamine-dependent serial connectivity linking the ventral with the dorsal striatum. Neuron 57, 432-441.

Bellone, C., and Lüscher, C. (2005). mGluRs induce a long-term depression in the ventral tegmental area that involves a switch of the subunit composition of AMPA receptors. Eur. J. Neurosci. 21, 1280-1288.

Bellone, C., and Lüscher, C. (2006). Cocaine triggered AMPA receptor redistribution is reversed in vivo by mGluR-dependent long-term depression. Nat. Neurosci. 9, 636-641.

Bellone, C., Lüscher, C., and Mameli, M. (2008). Mechanisms of synaptic depression triggered by metabotropic glutamate receptors. Cell. Mol. Life Sci. 65, 2913-2923.

Bellone, C., Mameli, M., and Lüscher, C. (2011). In utero exposure to cocaine delays postnatal synaptic maturation of glutamatergic transmission in the VTA. Nat. Neurosci. 14, 1439-1446.

Cartmell, J., and Schoepp, D. D. (2000). Regulation of neurotransmitter release by metabotropic glutamate receptors. J. Neurochem. 75, 889-907.

Choi, K. Y., Chung, S., and Roche, K. W. (2011). Differential binding of calmodulin to group I metabotropic glutamate receptors regulates receptor trafficking and signaling. J. Neurosci. 31, 5921-5930.

Conrad, K. L., Tseng, K. Y., Uejima, J. L., Reimers, J. M., Heng, L. J., Shaham, Y., Marinelli, M., and Wolf, M. E. (2008). Formation of accumbens GluR2-lacking AMPA receptors mediates incubation of cocaine craving. Nature 454, 118-121.

Deroche-Gamonet, V., Belin, D., and Piazza, P. V. (2004). Evidence for addiction-like behavior in the rat. Science 305, 1014-1017.

Dumont, E. C., Mark, G. P., Mader, S., and Williams, J. T. (2005). Selfadministration enhances excitatory synaptic transmission in the bed nucleus of the stria terminalis. Nat. Neurosci. 8, 413-414.

Fourgeaud, L., Mato, S., Bouchet, D., Hémar, A., Worley, P. F., and Manzoni, O. J. (2004). A single in vivo exposure to cocaine abolishes endocannabinoid-mediated long-term depression in the nucleus accumbens. J. Neurosci. 24, 6939-6945.

Galante, M., and Diana, M. A. (2004). Group I metabotropic glutamate receptors inhibit GABA release at interneuron-Purkinje cell synapses through endocannabinoid production. J. Neurosci. 24, 4865-4874.

Gass, J. T., and Olive, M. F. (2008). Glutamatergic substrates of drug addiction and alcoholism. Biochem. Pharmacol. 75, 218-265.

Grueter, B. A., Brasnjo, G., and Malenka, R. C. (2012). Postsynaptic TRPV1 triggers cell type-specific long-term depression in the nucleus accumbens. Nat. Neurosci. 13, 1519-1525.

Grueter, B. A., Gosnell, H. B., Olsen, C. M., Schramm-Sapyta, N. L., Nekrasova, T., Landreth, G. E., and Winder, D. G. (2006). Extracellularsignal regulated kinase 1-dependent metabotropic glutamate receptor 5bed nucleus of the stria terminalis is disrupted by cocaine administration. J. Neurosci. 26, 3210-3219.

Grueter, B. A., McElligott, Z. A., Robison, A. J., Mathews, G. C., and Winder, D. G. (2008). In vivo metabotropic glutamate receptor 5 (mGluR5) antagonism prevents cocaine-induced disruption of postsynaptically maintained mGluR5-dependent induced long-term depression in the

\section{ACKNOWLEDGMENTS}

We thank F. J. Meye and E. O'Connor for helpful comments on the manuscript. This work is supported by the Ecole de Neuroscience de Paris, Inserm Atip-Avenir, City of Paris (Manuel Mameli). Camilla Bellone is supported by the Swiss National Science Foundation Ambizione Fellowship.

long-term depression. J. Neurosci. 28, 9261-9270.

Hou, L., and Klann, E. (2004). Activation of the phosphoinositide 3-kinase-Akt-mammalian target of rapamycin signaling pathway is required for metabotropic glutamate receptor-dependent longterm depression. J. Neurosci. 24 6352-6361.

Huang, C. C., Yang, P. C., Lin, H. J., and Hsu, K. S. (2007). Repeated cocaine administration impairs group II metabotropic glutamate receptormediated long-term depression in rat medial prefrontal cortex. $\mathrm{J}$. Neurosci. 27, 2958-2968.

Jalabert, M., Aston-Jones, G., Herzog, E. Manzoni, O., and Georges, F. (2009). Role of the bed nucleus of the stria terminalis in the control of ventral tegmental area dopamine neurons. Prog. Neuropsychopharmacol. Biol. Psychiatry 33, 1336-1346.

Kalivas, P. W. (2004). Glutamate systems in cocaine addiction. Curr. Opin. Pharmacol. 4, 23-29.

Kalivas, P. W., Volkow, N., and Seamans, J. (2005). Unmanageable motivation in addiction: a pathology in prefrontal-accumbens glutamate transmission. Neuron 45, 647-650.

Kammermeier, P. J., Xiao, B., Tu, J. C. Worley, P. F., and Ikeda, S. R. (2000). Homer proteins regulate coupling of group I metabotropic glutamate receptors to $\mathrm{N}$-type calcium and $\mathrm{M}$ type potassium channels. J. Neurosci. 20, 7238-7245.

Kasanetz, F., Deroche-Gamonet, V., Berson, N., Balado, E., Lafourcade, M., Manzoni, O., and Piazza, P. V. (2010). Transition to addiction is associated with a persistent impairment in synaptic plasticity. Science 328, 1709-1712.

Kasanetz, F., Lafourcade, M., DerocheGamonet, V., Revest, J. M., Berson, N., Balado, E., Fiancette, J. F., Renault, P., Piazza, P. V., and Manzoni, O. J. (2012). Prefrontal synaptic markers of cocaine addictionlike behavior in rats. Mol. Psychiatry. doi: 10.1038/mp.2012.59. [Epub ahead of print]

Kauer, J. A., and Malenka, R. C. (2007) Synaptic plasticity and addiction. Nat. Rev. Neurosci. 8, 844-858.

Kumaresan, V., Yuan, M., Yee, J., Famous, K. R., Anderson, S. M., Schmidt,
H. D., and Pierce, R. C. (2009). Metabotropic glutamate receptor 5 (mGluR5) antagonists attenuate cocaine priming- and cue-induced reinstatement of cocaine seeking. Behav. Brain Res. 14, 238-244.

Lafourcade, M., Elezgarai, I., Mato, S., Bakiri, Y., Grandes, P., and Manzoni, O. J. (2007). Molecular components and functions of the endocannabinoid system in mouse prefrontal cortex. PLoS ONE 2, e709. doi:10.1371/journal.pone.0000709

Lu, L., Grimm, J. W., Hope, B. T., and Shaham, Y. (2004). Incubation of cocaine craving after withdrawal: a review of preclinical data. Neuropharmacology 47(Suppl 1), 214-226.

Lujan, R., Roberts, J. D., Shigemoto, R., Ohishi, H., and Somogyi, P (1997). Differential plasma membrane distribution of metabotropic glutamate receptors mGluR1 alpha, mGluR2 and mGluR5, relative to neurotransmitter release sites. J. Chem. Neuroanat. 13, 219-241.

Lüscher, C., and Huber, K. M. (2010). Group $1 \mathrm{mGluR}$-dependent synaptic long-term depression: mechanisms and implications for circuitry and disease. Neuron 65, 445-459.

Lüscher, C., and Malenka, R. C. (2011). Drug-evoked synaptic plasticity in addiction: from molecular changes to circuit remodeling. Neuron 69, 650-663.

Lüscher, C., and Ungless, M. A. (2006). The mechanistic classification of addictive drugs. PLoS Med. 3, e437. doi:10.1371/journal.pmed.0030437

Mameli, M., Balland, B., Luján, R., and Lüscher, C. (2007). Rapid synthesis and synaptic insertion of GluR2 for mGluR-LTD in the ventral tegmental area. Science 317, 530-533.

Mameli, M., Halbout, B., Creton, C., Engblom, D., Parkitna, J. R., Spanagel, R., and Lüscher, C. (2009). Cocaine-evoked synaptic plasticity: persistence in the VTA triggers adaptations in the NAc. Nat. Neurosci. 12, 1036-1041.

Mameli, M., Bellone, C., Brown, M. T., and Lüscher, C. (2011). Cocaine inverts rules for synaptic plasticity of glutamate transmission in the ventral tegmental area. Nat. Neurosci. 14, 414-416. 
Mato, S., Chevaleyre, V., Robbe, D., Pazos, A., Castillo, P. E., and Manzoni, O. J. (2004). A single invivo exposure to delta 9THC blocks endocannabinoid-mediated synaptic plasticity. Nat. Neurosci. 7, 585-586.

McCutcheon, J. E., Loweth, J. A., Ford, K. A., Marinelli, M., Wolf, M. E., and Tseng, K. Y. (2011a). Group I mGluR activation reverses cocaine-induced accumulation of calcium-permeable AMPA receptors in nucleus accumbens synapses via a protein kinase Cdependent mechanism. J. Neurosci. 31, 14536-14541.

McCutcheon, J. E., Wang, X., Tseng, K. Y., Wolf, M. E., and Marinelli, M. (2011b). Calcium-permeable AMPA receptors are present in nucleus accumbens synapses after prolonged withdrawal from cocaine self-administration but not experimenter-administered cocaine. J. Neurosci. 31, 5737-5743.

Moussawi, K., Pacchioni, A., Moran, M., Olive, M. F., Gass, J. T., Lavin, A., and Kalivas, P. W. (2009). $\mathrm{N}$-Acetylcysteine reverses cocaineinduced metaplasticity. Nat. Neurosci. 12, 182-189.

Niswender, C. M., and Conn, P. J. (2010). Metabotropic glutamate receptors: physiology, pharmacology, and disease. Annu. Rev. Pharmacol. Toxicol. 50, 295-322.

Olive, M. F. (2009). Metabotropic glutamate receptor ligands as potential therapeutics for addiction. Curr Drug Abuse Rev 2, 83-98.
Page, G., Khidir, F. A., Pain, S., Barrier, L., Fauconneau, B., Guillard, O., Piriou, A., and Hugon, J. (2006). Group I metabotropic glutamate receptors activate the p70S6 kinase via both mammalian target of rapamycin (mTOR) and extracellular signal-regulated kinase (ERK 1/2) signaling pathways in rat striatal and hippocampal synaptoneurosomes. Neurochem. Int. 49, 413-421.

Pascoli, V., Turiault, M., and Lüscher, C. (2012). Reversal of cocaine-evoked synaptic potentiation resets druginduced adaptive behaviour. Nature 481, 71-75.

Pierce, R. C., Bell, K., Duffy, P., and Kalivas, P. W. (1996). Repeated cocaine augments excitatory amino acid transmission in the nucleus accumbens only in rats having developed behavioral sensitization. J. Neurosci. $15,1550-1560$.

Pin, J. P., and Duvoisin, R. (1995). The metabotropic glutamate receptors: structure and functions. Neuropharmacology 34, 1-26.

Robbe, D., Alonso, G., Chaumont, S., Bockaert, J., Manzoni, O. J. (2002a). Role of p/q-Ca2+ channels in metabotropic glutamate receptor 2/3-dependent presynaptic long-term depression at nucleus accumbens synapses. J. Neurosci. 22, 4346-4356.

Saal, D., Dong, Y., Bonci, A., and Malenka, R. C. (2003). Drugs of abuse and stress trigger a common synaptic adaptation in dopamine neurons. Neuron 37, 577-582.
Spooren, W., Ballard, T., Gasparini, F., Amalric, M., Mutel, V., and Schreiber, R. (2003). Insight into the function of group I and group II metabotropic glutamate (mGlu) receptors: behavioural characterization and implications for the treatment of CNS disorders. Behav Pharmacol 14, 257-277.

Thomas, M. J., Beurrier, C., Bonci, A., and Malenka, R. C. (2001) Long-term depression in the nucleus accumbens: a neural correlate of behavioral sensitization to cocaine. Nat. Neurosci. 4, 1217-1223.

Ungless, M. A., Whistler, J. L., Malenka, R. C., and Bonci, A. (2001). Single cocaine exposure in vivo induces long-term potentiation in dopamine neurons. Nature 411, 583-587.

Upreti, C., Zhang, X. L., Alford, S. and Stanton, P. K. (2012). Role of presynaptic metabotropic glutamate receptors in the induction of longterm synaptic plasticity of vesicular release. Neuropharmacology. PMID: 22626985. [Epub ahead of print].

Wang, X., Moussawi, K., Knackstedt, L., Shen, H., and Kalivas, P. W. (2012). Role of mGluR5 neurotransmission in reinstated cocaine-seeking. Addict Biology. doi: 10.1111/j.13691600.2012.00479.x.

Xi, Z. X., Ramamoorthy, S., Baker, D. A., Shen, H., Samuvel, D. J., and Kalivas, P. W. (2002). Modulation of group II metabotropic glutamate receptor signaling by chronic cocaine. J. Pharmacol. Exp. Ther. 303 608-615.
Xie, X., and Steketee, J. D. (2008). Repeated exposure to cocaine alters the modulation of mesocorticolimbic glutamate transmission by medial prefrontal cortex Group II metabotropic glutamate receptors. J. Neurochem. 107, 186-196.

Zhou, W., and Kalivas, P. W. (2008). $\mathrm{N}$-acetylcysteine reduces extinction responding and induces enduring reductions in cue- and heroininduced drug-seeking. Biol. Psychiatry 63, 338-340.

Conflict of Interest Statement: The authors declare that the research was conducted in the absence of any commercial or financial relationships that could be construed as a potential conflict of interest.

Received: 20 July 2012; paper pending published: 01 August 2012; accepted: 09 August 2012; published online: 27 August 2012.

Citation: Bellone $C$ and Mameli $M$ (2012) mGluR-dependent synaptic plasticity in drug-seeking. Front. Pharmacol. 3:159. doi: 10.3389/fphar.2012.00159

This article was submitted to Frontiers in Neuropharmacology, a specialty of Frontiers in Pharmacology.

Copyright (c) 2012 Bellone and Mameli. This is an open-access article distributed under the terms of the Creative Commons Attribution License, which permits use, distribution and reproduction in other forums, provided the original authors and source are credited and subject to any copyright notices concerning any third-party graphics etc. 